\title{
Coverage and Determinants of Modern Contraceptive Use in Sub-saharan Africa: Further Analysis of Demographic and Health Surveys
}

Isaac Boadu ( $\sim$ iboadu002@st.ug.edu.gh )

Department of Population, Family and Reproductive Health, University of Ghana

\section{Research}

Keywords: Contraceptive, Determinants, Coverage, Sub-Sahara Africa

Posted Date: September 16th, 2021

DOl: https://doi.org/10.21203/rs.3.rs-882664/v1

License: (1) (1) This work is licensed under a Creative Commons Attribution 4.0 International License.

Read Full License

Version of Record: A version of this preprint was published at Reproductive Health on January 21st, 2022. See the published version at https://doi.org/10.1186/s12978-022-01332-x. 


\section{Abstract}

Background: The use of modern contraceptives (MC) in most African countries has been low despite the high fertility rate and unmet need for family planning. This study sought to determine the coverage and determinants of modern contraceptive use among women of reproductive age in Sub-Saharan Africa (SSA).

Methods: Data for the study was obtained from the latest Demographic and Health Surveys (DHS) conducted between 1995-2020 across 37 SSA countries. Women of reproductive age (15-19 years) was the unit of analysis. Analyses of data was done using STATA version 16 for windows. A bivariate Rao Scott's chi-square test of independence was done to determine factors associated with the use of modern contraceptives. Factors that showed significance $(p<0.05)$ were included in a multilevel logistic regression to determine significant predictors of modern contraceptives. Clustering, stratification and sample weighting were accounted for in the analyses.

Results: The overall prevalence of the use of MC was found to be $22.0 \%$. This ranged from $3.5 \%$ in the Central Africa Republic to $49.7 \%$ in Namibia. The most common type of contraceptives used were injections (39.4\%), condoms (17.5\%) and implants (26.5\%). Women were less likely to use contraceptive if they: had no education ( $\mathrm{aOR}=0.4,95 \% \mathrm{Cl}: 0.38-0.44)$, had no children $(\mathrm{aOR}=0.27-0.42)$, not told of family planning at a health facility $(\mathrm{aOR}=0.69,95 \% \mathrm{Cl}: 0.67-0.71)$, not heard of family planning in the media $(\mathrm{aOR}=0.77,95 \% \mathrm{Cl}: 0.74-0.79)$ and being poor $(\mathrm{aOR}=0.76,95 \% \mathrm{Cl}: 0.73-0.79)$. On the other hand, women were more likely to use modern contraceptive if they were between the age of 35-39 years $(\mathrm{aOR}=1.69,95 \% \mathrm{Cl}: 0.73-0.79)$, married $(\mathrm{aOR}=2.66,95 \% \mathrm{Cl}: 2.50-2.83)$, had seven or more children $(\mathrm{aOR}=1.27,95 \% \mathrm{Cl}: 1.17-0.38)$, had knowledge of any method of contraceptives (aOR=303.8, 95\% Cl: 89.9$1027.5)$ and when field worker visited and talked about family planning (aOR=1.53, 95\%Cl: 1.39-0.68).

Conclusion: The study showed a low prevalence of modern contraceptive use in Sub-Sahara Africa. Findings from the study highlight the need to provide education to women to increase uptake of contraceptive use and also re-enforce contraceptive interventions to improve women's health and wellbeing.

\section{Background}

Among the targets (3.7) in goal 3 of the United Nations sustainable development goals (SDGs) is to ensure universal access to sexual and reproductive healthcare services, including family planning, information and education, and the integration of reproductive health into national strategies and programs (1). Family planning (FP) has been defined by the World Health Organization (WHO) as a voluntary and informed decision by an individual or couple on the number of children to have and when to have them (2). It is characterized by the use of contraceptives, either modern or traditional methods. Modern contraceptive methods include male and female sterilization, male and female condoms, depot implants, pills, Lactational Amenorrhea Method (LAM), Intra-Uterine Devices (IUD), and emergency 
contraception (2). On the other hand, traditional methods comprise the withdrawal and rhyme method (periodic abstinence) (3). Of these two methods, modern contraceptive (contraceptive) has been recognized as an effective method for fertility reduction, and are being widely promoted to slow rapid population growth, particularly in developing countries $(4,5)$.

The use of MC has several benefits. These include birth spacing, reduce unwanted or unintended pregnancies, prevent unsafe abortions, improves maternal health, reduce infant mortality, and prevents sexually transmitted diseases (6). Identified non-health benefits include expanded education opportunities and empowerment for women, poverty reduction, and ensure sustainable population growth and economic development for countries (7). It is, therefore, necessary that information on the use of MC is made readily available and accessible to accelerate national efforts of achieving health goals.

Despite these established benefits of family planning, the use of MCis low especially in Sub-Saharan Africa countries (3). Globally, among the 1.9 billion women of reproductive age group (15-49 years) in 2019, 1.1 billion have a need for family planning; of these, 842 million are using contraceptive methods, and 270 million have an unmet need for contraception (2). Using countries in the family planning 2020 (FP2020) initiative, the average prevalence of modern contraceptive use was estimated to be $23.9 \%$ and $28.5 \%$ among married women and those engaged in relationships between 2012 and 2017 respectively (3).

In 2012 and 2017 the prevalence of modern contraceptive use among married women or those in relationships in Africa was reported to be low: estimated at $23.9 \%$ and $28.5 \%$ respectively (3). In a recent large population-based study to estimate the prevalence and factors associated with modern contraceptive use among women of reproductive age in 20 African countries, Ayampa et al., (8) reported a $26 \%$ prevalence of modern contraceptive use with a country-specific variation of $6 \%$ in Guinea to $62 \%$ in Zimbabwe.

The factors that influence contraceptive practice are multidimensional and have been reported to range from knowledge of contraceptives methods, socio-demographic characteristics (age, education, religion, level of income, marital status, employment), parity, number of living children, source of reproductive information, frequency of antenatal visits, terminated pregnancy, prior HIV testing, residence (rural or urban), literacy, being sexually active, partners communication and approval and fear of side effects of contraceptives $(9-16)$.

Earlier studies on modern contraceptive use in Africa have focused on individual countries $(9-11,13,17-$ 19). Very few studies have assessed the prevalence and use of $M C$ across Africa $(8,20-22)$. This paucity of information was the drive to this study on the holistic assessment of the prevalence and determinants of modern contraceptive use in the Sub-Sahara African region. The study therefore aimed at assessing the coverage and determinants of modern contraceptive use among women of reproductive age (15-49 years) using the available recent demographic and health survey data of Sub-Saharan African countries. Findings for this study are important in the global and local context, particularly within the African region to improve maternal and child health outcomes. 


\section{Methods}

\section{Patient and public involvement}

Patient were not involved in this study.

\section{Data source, sampling design and study population}

In this study, secondary data of demographic and health survey (DHS) of Sub-Sahara Africa countries were used. DHS is a nationally representative household sample survey that evaluates population sociodemographics, maternal and child health, and a variety of health indicators including the use of contraceptives. The DHS is a valuable source of data for studying population health indicators because of its coverage, data quality, and comparability throughout the world. In addition, the sample used is generally representative at the national, regional, and residence (rural and urban) level. DHS sampling is based on a two-stage cluster design approach. In the first stage, there is stratification and proportional allocation of the sample frame. The second stage involves a selection of households per cluster with equal probabilities in a systematic approach. Details of the sampling design and sampling procedure can be found at the DHS program websites (www.dhsprogram.com/methodology/survey-types/DHS).

The available recent demographic and health survey (DHS) conducted in 37 Sub-Sahara Africa countries from 1995 to 2020 were included in this study. These countries include Angola, Benin, Burkina Faso, Burundi, Cameroon, Central African Republic, Comoros, Congo, Congo Democratic, Cote d'Ivoire, Eswatini, Ethiopia, Gabon, Gambia, Ghana, Guinea, Kenya, Lesotho, Liberia, Madagascar, Malawi, Mali, Mozambique, Namibia, Niger, Nigeria, Rwanda, Sao Tome and Principle, Senegal, Sierra Leone, South Africa, Sudan, Tanzania, Togo, Uganda, Zambia and, Zimbabwe. Data were downloaded from the DHS programme website (www.dhsprogram.com) after granting permission. The data archive at the DHS website had 38 Sub-Sahara Africa countries excluding Ondo State in Nigeria. Chad was not included because of its extremely old data (1990) and was missing most of the independent variables of interest as well as lack of stratification. The unit of analysis in this study was women of reproductive age (15-49 years).

\section{Definition of variables}

\section{Outcome variable}

The current use of MC by women of reproductive age (15-49 years) was the primary outcome of interest. This was dichotomized as "use of a modern method (coded as " 1 ") and non-use of modern contraceptive (coded as " 0 "). Modern contraceptive was described as the use of any of the following contraceptive methods: sterilization (female), intrauterine system (IUD), injectable, implant, tablets, condom (female), standard days method (SDM), emergency contraception, diaphragm, foam/jelly, diaphragm, countryspecific modern methods, and other modern contraceptive methods respondent mentioned (including cervical cap, contraceptive sponge, and others) but does not include abortion, menstrual regulation as described in the DHS questionnaire. Traditional methods included periodic abstinence (rhythm, calendar 
method), withdrawal (coitus interruptus) and country-specific traditional methods of proven effectiveness, and folk methods including locally described methods and/or spiritual methods such as herbs, amulets, gris-gris, etc.

\section{Independent variables}

The independent variables considered in this study include socio-demographic characteristics such as the age of the respondent ("15-19", "20-24, 25-29", "30-34", "35-39", "40-44" and "45-49"), age at first birth, recoded ("no birth", "<20", "20-29" and 29+), education ("no education", "Primary", "secondary" and "higher"), husband/partners education ("no education", "Primary", "secondary" and "higher" "don't know") religion, recoded ("Christian", "Islamic", "Traditional" and "Other"), marital status, recoded ("Never married" "Married", "Co-habiting" and "Other"), wealth index, recoded ("poorer/poorest", "Middle" and "Richer/Richest"), Employment ("working" and "not working"). Others include the number of living children, recoded ("0", "1-2", "3-4", "5-7" and "7+"), source of reproductive information, recoded as media (radio, television, newspaper, text messages, "Yes" and "No"), been told of family planning at a health facility ("Yes" and "No"), place of residence ("rural" or "urban"), the number of sex partners excluding the spouse, recoded ("none", "1", "2", "3+" and "don't know") and knowledge of modern contraceptive ("Yes" and "No"), field worker visited and talked about family planning ("Yes" and "No") and visited health facility in the last 12 months ("Yes" and "No"). These variables were chosen based on previous studies (8, $14,16,22)$.

\section{Data analyses}

Data for this study were analyzed using STATA version 16 for windows. Data were cross-checked for missing data and no response or interviewer error (9 or 99) and were excluded in the analyses. Again, missing data associated with the outcome variable, use of modern contraceptives, were dropped from the analyses. Descriptive statistics were summarised for demographic characteristics and prevalence of the use of MC in each country. A bivariate analysis (Rao Scott's $X^{2}$ ) was done to determine the association of socio-demographic characteristics, questions relating to the use of contraceptives, and the outcome variable (use of modern contraceptive). Variables that showed significance in the bivariate analysis were used for the multiple logistic regression analyses. The independent variables were checked for multicolinearity before the multiple logistic regression. Sample weight was adjusted by dividing the individual women's sample weight by $1000,000\left(\mathrm{v} 005 / 10^{6}\right)$. In all analyses, clustering, stratification, and applied sampling weights were accounted for to reduce bias and to improve on the adjusted estimates and standard errors as recommended in complex survey design analysis. A p $<0.05$ was considered statistically significant.

\section{Ethical Approval}

This study required no ethical clearance as secondary data was used. However, written permission was sought and was granted from the DHS program before data access. 


\section{Results}

\section{Socio-demographic characteristics of participants}

The final sample size of women of reproductive age (15-49 years) for the 37 Sub-Saharan Africa countries included in the analyses was 494,285. As of the time of this study, the countries with the most recent DHS data were Liberia (2020), Senegal (2019), and Sierra Leone (2019). Central African Republic had the oldest DHS data (see Table 1).

The mean age of the women was $28.5 \pm 0.02$ years (95\% Cl: $28.5-28.6 \%)$ with $21.2 \%$ within the age of $15-19$ years. About a third had their highest education in secondary $(32.5 \%)$ and primary $(32.2 \%)$. With respect to the educational level of their husbands/partners, 33.3, 27.8, 28.3, and $7.4 \%$ had no formal education, primary, secondary, and higher education. Most of the women $(60.8 \%)$ resided in rural settings and were employed (60.0\%). About half (50.9\%) were married. With regards to wealth index, $35.9 \%$, were poor/poorest and $44.9 \%$ were rich/richest. More than a quarter of the women had $1-2(28.2 \%)$ and $3-4$ (28.9\%) living children. Women had heard of family planning on the media (42.6\%) and had been told of family planning at a health facility (36.1\%). Details of socio-demographic and sexual and reproductive characteristics are presented in Table 2.0.

\section{Prevalence of Modern Contraceptive Use}

The pooled prevalence of modern contraceptive use was $22.0 \%$ (95\% Cl: $21.8-22.2 \%)$. Coverage varied considerably across countries, ranging from the highest, $49.7 \%$ (95\% Cl: $48.4-51.1 \%)$ in Namibia to lowest, 3.5\% (95\% Cl: 3.0-4.1\%) in Central Africa Republic. Other countries that had high prevalence of MC use were Lesotho, 48.5\% (95\% Cl: 21.8-22.2\%), Zimbabwe, 47.9\% (95\% Cl: 46.5-49.2\%), South Africa, 47.9\% (95\% Cl: 46.2-49.5\%), Malawi, 45.2\% (95\% Cl: 44.2-46.1\%) and Kenya, 39.1\% (95\% Cl: 38.2-40.0\%) (Fig. 1.0). The most commonly used family planning method (modern contraceptives) were injections (39.4\%), male condoms (17.5\%), implants (16.5\%), and pills (15.7\%) (Fig. 2).

\section{Factors associated with Modern Contraceptive Use}

In a bivariate analysis (Rao Scott's $X^{2}$ ), all the socio-demographic characteristics used in the study (educational level, place of residence, religion, employment status, marital status, and wealth index), as well as the reproductive and sexual characteristics, were significantly associated with the use of modern contraceptive $(p<0.05)$.

In a multilevel logistic regression model (Table 3), women aged 35-39 years had higher odds [aOR $=1.69$, $95 \% \mathrm{Cl}(1.58-1.80)]$ of using MC compared with women aged 15-19 years. Women with no formal education were less likely to use $\mathrm{MC}[\mathrm{aOR}=0.4,95 \% \mathrm{Cl}(0.38-0.44)]$ compared with women with higher education. Living in rural areas was less associated [aOR $=0.76 ;(0.72-0.89)]$ with the use of $\mathrm{MC}$ compared with living in urban areas. Women who were Christians were more likely to use $\mathrm{MC}$ than other types of religion $(\mathrm{aOR}=1.3,95 \% \mathrm{Cl} ; 1.17-1.38)$. Being poor/poorest $[\mathrm{aOR}=0.76,95 \% \mathrm{Cl}(0.73-0.79)]$ and 
belonging to the middle-class wealth index [aOR $=0.98,95 \% \mathrm{Cl}(0.80-1.20)]$ were less associated with the use of modern contraceptive use compared with rich or richest women. Women with 5-7 children were more likely to use $\mathrm{MC}[\mathrm{aOR}=1.27,95 \% \mathrm{Cl}(1.17-1.38)]$.

Having more (3+) multiple sexual partners excluding spouse was associated with higher odds [aOR = $9.57,95 \% \mathrm{Cl}(6.62-13.84)]$ of the use of $\mathrm{MC}$ compared with having no multiple sexual partners. Women who were not told of family planning at a health facility were less likely [aOR $=0.69,95 \% \mathrm{Cl}(0.67-0.71)$ ] to use MCcompared with women who had heard family planning from a health facility. Knowing any modern method of contraceptive was 303.8 times associated with the use of $\mathrm{MC}$ [aOR $=303.8,95 \% \mathrm{Cl}$ (89.9-1027.5)] than those who did not know any method. Women who had not heard of family planning from television, radio, and text messages (media as a source of information) were less likely to use MC $[\mathrm{aOR}=0.77,95 \% \mathrm{Cl}(0.74-0.79)]$ compared with those who have heard of family planning from the media.

\section{Discussion}

Family planning is one of the investments that can be made to help achieve most of the United Nation's sustainable development goals especially poverty reduction, quality education, decent work and economic growth, and good health and well-being. The use of $M C$ is a safe and effective method to regulate fertility and ensure the well-being of women of reproductive age. Coverage and factors associated with the use of MC vary across the globe including Sub-Sahara Africa countries.

In this study, the pooled prevalence of MC use was low, 22.0\%; with country-specific variations. Namibia recorded the highest reproductive women using MC (49.7\%) with the least in Central Africa Republic (3.5\%). This finding is similar to a recent study using secondary data of DHS in 29 Sub-Sahara Africa countries on predictors among adolescent and young women, where Ahenkorah (22) reported a prevalence of $24.7 \%$. Again, the finding is in agreement with a study by Apanga et al. (8) who used data from multiple indicator cluster surveys across 20 Africa countries. The authors reported an overall prevalence of $26 \%$ ranging from $6 \%$ in Guinea and $62 \%$ in Zimbabwe. In addition, this finding is also consistent with country-specific DHS studies $(9,16,23-27)$.

The most common type of contraceptives used were injections (39.4\%), condoms (17.5\%), and implants $(26.5 \%)$. Earlier studies have reported similar findings $(9,12)$. Factors associated with modern contraceptive use include age, women's educational level, educational level of husband/partner, place of residence, employment, marital status, wealth index, number of living children, been told of family planning at a health facility, number of sex partners excluding the spouse, heard family planning on the media (television, radio, newspaper, text messages), knowledge of modern method and a visit by a health worker to discuss family planning.

In this present study, younger aged women (15-19 years) were less likely to use MC compared to older old women (35-39 years). This could be due to the fact that, these old women were having more children and would want to limit or space the number of pregnancies than the younger women who may have few or no children. This was confirmed in the findings where women with more children were less likely to use 
modern contraceptives. This finding is in line with previous studies $(12,28)$ but contradicts the findings of these studies $(22,29)$ where younger women were more likely to use modern contraceptives.

In most African countries family planning is part of integrated health care. Health workers continue to play a major role in encouraging the use of $\mathrm{MC}$ by providing couples with the knowledge that enables them to make informed reproductive decisions including the use of MC (30). Findings from this study indicate that women who had received family planning information from health workers were more likely to use MCthan those who did not. This is in agreement with the study by Kebede and colleagues (12).

Women residing in rural areas were less likely to use $M C$ than those in urban settings. This could be due to accessibility, availability, and lack of information on the use of $\mathrm{MC}$ in these settings. Consistent with this finding is the study by Kebede et al., Ontiri et al and Mahmood and Ringheim $(12,19,31)$.

The media serves as a source of information and is mostly used to provide vital information to the public. In this study, women who reported receiving information from the media (television, radio, newspaper, text messages) or exposed to the media were more likely to use modern contraceptives. This is similar to earlier studies that reported on the strong influence and association of the media and uptake of MC (32, 33).

Having adequate reproductive knowledge helps with better decisions. A finding from this study is that knowledge of any method of contraceptives was significantly associated with the use of modern contraceptives. This is in agreement with previous studies $(12,34)$. It is therefore imperative that much reproductive information is provided to women to increase their knowledge to guide good reproductive decisions to improve their health and well-being.

\section{Strength and limitation of the study}

The strength of this study is the large population-based sample size used in the study which increased the power of the study. This enables the generalizability of the findings of modern contraceptive use among women of reproductive age. However, the study was limited by the use of secondary data restricting study variables.

\section{Conclusion}

There was a low pooled prevalence (22.0\%) of the use of MC across the 37 countries used in SubSaharan Africa. This showed a considerable variation from as low as $3.5 \%$ in the Central Africa Republic to $49.7 \%$ in Namibia. The most common type of contraceptives used were injections (39.4\%), condoms (17.5\%), and implants (26.5\%). Socio-demographic, sexual characteristics factors were found to be associated with the use of modern contraceptives. The low prevalence of modern contraceptive use recorded in this study infers that there should be more education particularly in the health facility and the media to increase knowledge and uptake of MC use among women of reproductive age. 


\section{Abbreviations}

DHS: Demographic and Health Survey, SSA: sub-Saharan Africa, MC: Modern Contraceptive, aOR: adjusted Odds Ratio, LAM: Lactational Amenorrhea Method, IUD: Intra-Uterine Devices, FP: Family planning.

\section{Declarations}

\section{Acknowledgment}

The author gratefully acknowledges the DHS program for making data available for the study.

\section{Funding}

Not applicable

\section{Availability of data and materials}

All datasets and materials supporting our findings are available from the DHS program website.

\section{Ethics approval and consent to participate}

Ethical approval was not required for the study as secondary data was used.

\section{Authors' contributions}

IB designed the research, analyzed the data, and wrote the first draft, and approved the final manuscript.

\section{Conflict of interest}

The author declares no conflict of interest.

\section{Consent for publication}

Not applicable

\section{References}

1. United Nations Sustainable development goals. Goals 3; Ensure healthy lives and promote well-being for all at all ages; Targets and Indicators. Available at https://sdgs.un.org/goals/goal3, 2019. Accessed 20/05/2021.

2. WHO, Family planning/contraception methods. Available at https://www.who.int/news-room/factsheets/detail/family-planning-contraception, 2020. Accessed 3/03/2021.

3. Cahill, N., et al., Modern contraceptive use, unmet need, and demand satisfied among women of reproductive age who are married or in a union in the focus countries of the Family Planning 2020 
initiative: a systematic analysis using the Family Planning Estimation Tool. 2018. 391(10123): p. 870-882.

4. Festin, M.P.R., et al., Moving towards the goals of FP2020-classifying contraceptives. 2016. 94(4): p. 289-294.

5. Marquez, M.P., M.M. Kabamalan, and E.J.S.i.f.p. Laguna, Traditional and Modern Contraceptive Method Use in the Philippines: Trends and Determinants 2003-2013. 2018. 49(2): p. 95-113.

6. Frost, J.J. and L.D.J.C. Lindberg, Reasons for using contraception: perspectives of US women seeking care at specialized family planning clinics. 2013. 87(4): p. 465-472.

7. Starbird, E., et al., Investing in family planning: key to achieving the sustainable development goals. 2016. 4(2): p. 191-210.

8. Apanga, P.A., et al., Prevalence and factors associated with modern contraceptive use among women of reproductive age in 20 African countries: a large population-based study. BMJ Open, 2020. 10(9): p. e041103.

9. Gebre, M.N. and Z.K. Edossa, Modern contraceptive utilization and associated factors among reproductive-age women in Ethiopia: evidence from 2016 Ethiopia demographic and health survey. BMC Womens Health, 2020. 20(1): p. 61.

10. Andi, J.R., et al., Modern contraceptive use among women in Uganda: An analysis of trend and patterns (1995-2011). Etude Popul Afr, 2014. 28(2): p. 1009-1021.

11. Johnson, O.E., Determinants of Modern Contraceptive Uptake among Nigerian Women: Evidence from the National Demographic and Health Survey. African Journal of Reproductive Health, 2017. 21(3): p. 89.

12. Kebede, A., et al., Factors affecting demand for MCamong currently married reproductive age women in rural Kebeles of Nunu Kumba district, Oromia, Ethiopia. Contracept Reprod Med, 2019. 4: p. 21.

13. Palamuleni, M.E., Socio-Economic and Demographic Factors Affecting Contraceptive use in Malawi. African Journal of Reproductive Health, 2013. 13(3).

14. Solanke, B.L., Factors influencing contraceptive use and non-use among women of advanced reproductive age in Nigeria. J Health Popul Nutr, 2017. 36(1): p. 1.

15. Tawiah, E.O., Factors affecting contraceptive use in Ghana. J Biosoc Sci, 1997. 29(2): p. 141-9.

16. Nonvignon, J. and J. Novignon, Trend and determinants of contraceptive use among women of reproductive age in Ghana. African Population Studies, 2014. 28: p. 956-967.

17. Aviisah, P.A., et al., Modern contraceptive use among women of reproductive age in Ghana: analysis of the 2003-2014 Ghana demographic and health surveys. 2018. 18(1): p. 1-10.

18. Achana, F.S., et al., Spatial and socio-demographic determinants of contraceptive use in the Upper East region of Ghana. Reprod Health, 2015. 12: p. 29.

19. Ontiri, S., et al., Patterns and determinants of modern contraceptive discontinuation among women of reproductive age: Analysis of Kenya Demographic Health Surveys, 2003-2014. PLoS One, 2020. 15(11): p. e0241605. 
20. Ba, D.M., et al., Prevalence and predictors of contraceptive use among women of reproductive age in 17 sub-Saharan African countries: a large population-based study. 2019. 21: p. 26-32.

21. Stephenson, R., et al., Contextual influences on modern contraceptive use in sub-Saharan Africa. Am J Public Health, 2007. 97(7): p. 1233-40.

22. Ahinkorah, B.O., Predictors of modern contraceptive use among adolescent girls and young women in sub-Saharan Africa: a mixed effects multilevel analysis of data from 29 demographic and health surveys. Contracept Reprod Med, 2020. 5(1): p. 32.

23. Lakew, Y., et al., Geographical variation and factors influencing modern contraceptive use among married women in Ethiopia: evidence from a national population based survey. Reproductive health, 2013. 10(1): p. 1-10.

24. Aviisah, et al., Modern contraceptive use among women of reproductive age in Ghana: analysis of the 2003-2014 Ghana Demographic and Health Surveys. BMC Womens Health, 2018. 18(1): p. 141.

25. Butame, S.A., The prevalence of modern contraceptive use and its associated socio-economic factors in Ghana: evidence from a demographic and health survey of Ghanaian men. Public Health, 2019. 168: p. 128-136.

26. Mandiwa, C., et al., Factors associated with contraceptive use among young women in Malawi: analysis of the 2015-16 Malawi demographic and health survey data. Contracept Reprod Med, 2018. 3: p. 12.

27. Worku, A.G., G.A. Tessema, and A.A. Zeleke, Trends of modern contraceptive use among young married women based on the 2000, 2005, and 2011 Ethiopian Demographic and Health Surveys: a multivariate decomposition analysis. PLoS One, 2015. 10(1): p. e0116525.

28. Takele, A., G. Degu, and M. Yitayal, Demand for long acting and permanent methods of contraceptives and factors for non-use among married women of Goba Town, Bale Zone, South East Ethiopia. Reproductive health, 2012. 9(1): p. 1-11.

29. Grindlay, K., et al., Contraceptive use and unintended pregnancy among young women and men in Accra, Ghana. PloS one, 2018. 13(8): p. e0201663.

30. Kabagenyi, A., et al., Modern contraceptive use among sexually active men in Uganda: does discussion with a health worker matter? BMC Public Health, 2014. 14(1): p. 1-8.

31. Mahmood, N. and K. Ringheim, Factors affecting contraceptive use in Pakistan. The Pakistan Development Review, 1996: p. 1-22.

32. Bajoga, U.A., K.L. Atagame, and C.C. Okigbo, Media influence on sexual activity and contraceptive use: a cross sectional survey among young women in urban Nigeria. African Journal of Reproductive Health, 2015. 19(3): p. 100-110.

33. Rutaremwa, G., et al., Predictors of modern contraceptive use during the postpartum period among women in Uganda: a population-based cross sectional study. BMC public health, 2015. 15(1): p. 1-9.

34. Weldegerima, B. and A. Denekew, Women's knowledge, preferences, and practices of modern contraceptive methods in Woreta, Ethiopia. Research in Social and Administrative pharmacy, 2008. 4(3): p. 302-307. 


\section{Tables}

Page $12 / 23$ 
Table 1

Country Specific Sample Size and Survey Year of the DHS

\begin{tabular}{|c|c|c|c|}
\hline Country & Year & Sample & \% Sample \\
\hline Angola & $2015-2016$ & 14379 & 2.9 \\
\hline Benin & $2017-2018$ & 15928 & 3.2 \\
\hline Burkina Faso & 2010 & 17087 & 3.5 \\
\hline Burundi & $2016-2017$ & 17269 & 3.5 \\
\hline Cameroon & 2018 & 13527 & 2.7 \\
\hline Central African Republic & 1994-1995 & 5884 & 1.2 \\
\hline Chad & $2014-2015$ & 17719 & 3.6 \\
\hline Comoros & 2012 & 5329 & 1.1 \\
\hline Congo & $2011-2012$ & 10819 & 2.2 \\
\hline Congo Democratic Republic & $2013-2014$ & 18827 & 3.8 \\
\hline Cote d'ivoire & $2011-2012$ & 10060 & 2.0 \\
\hline Eswatini & $2006-2007$ & 4987 & 1.0 \\
\hline Ethiopia & 2016 & 15683 & 3.2 \\
\hline Gabon & 2012 & 8422 & 1.7 \\
\hline Gambia & 2013 & 10233 & 2.1 \\
\hline Ghana & 2014 & 9396 & 1.9 \\
\hline Guinea & 2018 & 10874 & 2.2 \\
\hline Kenya & 2014 & 31079 & 6.3 \\
\hline Lesotho & 2014 & 6621 & 1.3 \\
\hline Liberia & $2019-2020$ & 8065 & 1.6 \\
\hline Madagascar & $2008-2009$ & 17375 & 3.5 \\
\hline Malawi & $2015-2016$ & 24562 & 5.0 \\
\hline Mali & 2018 & 10519 & 2.1 \\
\hline Mozambique & 2011 & 13745 & 2.8 \\
\hline Namibia & 2013 & 9176 & 1.9 \\
\hline Niger & 2012 & 11160 & 2.3 \\
\hline
\end{tabular}




\begin{tabular}{|llll|}
\hline Country & Year & Sample & \% Sample \\
\hline Nigeria & 2018 & 41821 & 8.5 \\
\hline Rwanda & $2014-2015$ & 13497 & 2.7 \\
\hline Sao Tome and Principle & $2008-2009$ & 2615 & 0.5 \\
\hline Senegal & 2019 & 8649 & 1.8 \\
\hline Sierra Leone & 2019 & 15574 & 3.2 \\
\hline South Africa & 2016 & 8514 & 1.7 \\
\hline Tanzania & $2015-2016$ & 13266 & 2.7 \\
\hline Togo & $2013-2014$ & 9480 & 1.9 \\
\hline Uganda & 2016 & 18506 & 3.7 \\
\hline Zambia & 2018 & 13683 & 2.8 \\
\hline Zimbabwe & 2015 & 9955 & 2.0 \\
\hline Total: & & 494,285 & 100.0 \\
\hline DHS: Demographic and Health Survey & & \\
\hline
\end{tabular}


Table 2

Socio-demographic and sexual and reproductive characteristics associated with the use of MC

$\begin{array}{lllll}\text { Variable } & \text { Weighted } & \text { Weighted } & \begin{array}{l}\text { \%Modern } \\ \text { Contraceptive Use }\end{array} & \begin{array}{l}\text { Rao } \\ \text { Scott's }\end{array} \\ & \% & & \mathrm{X}^{2} \\ & & & \text { (p-value) }\end{array}$

Age group $[28.5 \pm 0.02,(28.5$,

28.6) $\left.{ }^{*}\right]$

\begin{tabular}{|c|c|c|c|c|}
\hline $15-19$ & 104795 & 21.2 & 9.0 & \multirow{7}{*}{$\begin{array}{l}1523.6(< \\
0.01)\end{array}$} \\
\hline $20-24$ & 91263 & 18.5 & 23.9 & \\
\hline $25-29$ & 86634 & 17.5 & 27.9 & \\
\hline $30-34$ & 71274 & 14.4 & 28.9 & \\
\hline $35-39$ & 59784 & 12.1 & 27.6 & \\
\hline $40-44$ & 44301 & 9.0 & 23.8 & \\
\hline $45-49$ & 36323 & 7.4 & 15.2 & \\
\hline \multicolumn{5}{|c|}{ Highest Educational Level } \\
\hline No Education & 147697 & 29.9 & 11.9 & \multirow{4}{*}{$\begin{array}{l}1439.4 \\
(<0.01)\end{array}$} \\
\hline Primary & 160181 & 32.4 & 25.6 & \\
\hline Secondary & 160531 & 32.5 & 25.9 & \\
\hline Higher & 25925 & 5.24 & 32.1 & \\
\hline
\end{tabular}

Highest Educational level of husband/partner

No education

$107539 \quad 33.3$

12.7

1362.0

$(<0.01)$

\begin{tabular}{llll} 
Primary & 89945 & 27.8 & 29.9 \\
Secondary & 91573 & 28.3 & 29.4 \\
Higher & 23960 & 7.4 & 32.1 \\
\hline Don't know & 10198 & 3.2 & 18.9
\end{tabular}

Place of Residence

Urban

$193678 \quad 39.2$

24.8

245.5

$(<0.01)$

${ }^{*}$ Mean \pm Standard error 


\begin{tabular}{|c|c|c|c|c|}
\hline Variable & $\begin{array}{l}\text { Weighted } \\
\mathbf{N}\end{array}$ & $\begin{array}{l}\text { Weighted } \\
\%\end{array}$ & $\begin{array}{l}\text { \%Modern } \\
\text { Contraceptive Use }\end{array}$ & $\begin{array}{l}\text { Rao } \\
\text { Scott's } \\
X^{2} \\
\text { (p-value) }\end{array}$ \\
\hline Rural & 300696 & 60.8 & 20.1 & \\
\hline \multicolumn{5}{|l|}{ Employment } \\
\hline No & 190888 & 40.0 & 18.6 & \multirow{2}{*}{$\begin{array}{l}510.2 \\
(<0.01)\end{array}$} \\
\hline Yes & 286403 & 60.0 & 23.3 & \\
\hline \multicolumn{5}{|l|}{ Marital Status } \\
\hline Never married & 137041 & 27.7 & 14.54 & \multirow{4}{*}{$\begin{array}{l}674.7 \\
(<0.01)\end{array}$} \\
\hline Married & 251395 & 50.9 & 25.59 & \\
\hline Co-habiting & 61897 & 12.5 & 24.09 & \\
\hline $\begin{array}{l}\text { Other (widowed/divorced/no } \\
\text { longer living with partner) }\end{array}$ & 44038 & 8.9 & 21.32 & \\
\hline \multicolumn{5}{|l|}{ Religion } \\
\hline \multirow[t]{2}{*}{ Christian } & \multirow[t]{2}{*}{289346} & \multirow[t]{2}{*}{64.6} & \multirow[t]{2}{*}{25.8} & 1392.7 \\
\hline & & & & $(<0.01)$ \\
\hline Islamic & 133440 & 29.8 & 12.4 & \\
\hline Traditional & 6984 & 1.6 & 9.4 & \\
\hline Other & 18079 & 4.0 & 18.1 & \\
\hline \multicolumn{5}{|l|}{ Wealth Index } \\
\hline Poorer/poorest & 175432 & 35.9 & 18.0 & \multirow{3}{*}{$\begin{array}{l}500.1 \\
(<0.01)\end{array}$} \\
\hline Middle & 93856 & 19.2 & 22.2 & \\
\hline Richer/Richest & 219202 & 44.9 & 25.6 & \\
\hline \multicolumn{5}{|l|}{ Number of living children } \\
\hline None & 137905 & 27.9 & 9.1 & \multirow{4}{*}{$\begin{array}{l}2334.6 \\
(<0.01)\end{array}$} \\
\hline $1-2$ & 149521 & 30.2 & 28.2 & \\
\hline $3-4$ & 110897 & 22.4 & 28.9 & \\
\hline $5-7$ & 80183 & 16.2 & 23.9 & \\
\hline
\end{tabular}




\begin{tabular}{|c|c|c|c|c|}
\hline Variable & $\begin{array}{l}\text { Weighted } \\
\text { N }\end{array}$ & $\begin{array}{l}\text { Weighted } \\
\%\end{array}$ & $\begin{array}{l}\text { \%Modern } \\
\text { Contraceptive Use }\end{array}$ & $\begin{array}{l}\text { Rao } \\
\text { Scott's } \\
X^{2} \\
\text { (p-value) }\end{array}$ \\
\hline $7+$ & 15867 & 3.2 & 16.9 & \\
\hline \multicolumn{5}{|l|}{$\begin{array}{l}\text { Told family planning at a } \\
\text { health facility }\end{array}$} \\
\hline No & 158281 & 63.9 & 34.0 & \multirow{2}{*}{$\begin{array}{l}567.2 \\
(<0.01)\end{array}$} \\
\hline Yes & 89367 & 36.1 & 23.0 & \\
\hline \multicolumn{5}{|c|}{ Number of sex partners excluding spouse } \\
\hline None & 391272 & 85.5 & 18.9 & \multirow{5}{*}{$\begin{array}{l}1088.8 \\
(<0.01)\end{array}$} \\
\hline 1 & 60613 & 13.3 & 35.7 & \\
\hline 2 & 5070 & 1.1 & 44.0 & \\
\hline $3+$ & 575 & 0.1 & 48.7 & \\
\hline Don't know & 46 & 0.01 & 59.2 & \\
\hline \multicolumn{4}{|l|}{$\begin{array}{l}\text { Heard Family Planning on } \\
\text { the Media }\end{array}$} & \multirow{3}{*}{$\begin{array}{l}4321.1 \\
(p<0.01)\end{array}$} \\
\hline No & 283556 & 57.4 & 17.4 & \\
\hline Yes & 210818 & 42.6 & 28.0 & \\
\hline \multicolumn{5}{|l|}{ Age at first birth $(19.3 \pm 0.1)^{*}$} \\
\hline No birth & 133134 & 26.93 & 9.00 & $\begin{array}{l}3019(< \\
0.01)\end{array}$ \\
\hline$<20$ & 215240 & 43.54 & 26.22 & \\
\hline $20-29$ & 138774 & 28.07 & 27.93 & \\
\hline$>29$ & 7225 & 1.46 & 19.07 & \\
\hline \multicolumn{5}{|l|}{$\begin{array}{l}\text { Knowledge of modern } \\
\text { method }\end{array}$} \\
\hline No & 30815 & 7.2 & 0.01 & \multirow{2}{*}{$\begin{array}{l}9075.9 \\
(<0.01)\end{array}$} \\
\hline Yes & 463558 & 92.8 & 23.42 & \\
\hline \multicolumn{5}{|c|}{ Fieldworker visited and talked about family planning } \\
\hline
\end{tabular}




\begin{tabular}{|c|c|c|c|c|}
\hline Variable & $\begin{array}{l}\text { Weighted } \\
\mathbf{N}\end{array}$ & $\begin{array}{l}\text { Weighted } \\
\%\end{array}$ & $\begin{array}{l}\text { \%Modern } \\
\text { Contraceptive Use }\end{array}$ & $\begin{array}{l}\text { Rao } \\
\text { Scott's } \\
X^{2} \\
\text { (p-value) }\end{array}$ \\
\hline No & 19861 & 53.0 & 11.3 & \multirow{2}{*}{$\begin{array}{l}309.8 \\
(< \\
0.01)\end{array}$} \\
\hline Yes & 17623 & 47.0 & 15.6 & \\
\hline \multicolumn{5}{|c|}{$\begin{array}{l}\text { Visited Health Facility last } 12 \\
\text { months }\end{array}$} \\
\hline No & 229948 & 48.1 & 7.4 & \multirow{2}{*}{$\begin{array}{l}4342.4 \\
(< \\
0.01)\end{array}$} \\
\hline Yes & 247798 & 51.9 & 14.0 & \\
\hline
\end{tabular}


Table 3

Factors associated with the use of Modern Contraceptive use among Women (15-49 years)

\section{Age group (years)}

$15-19$

$20-24$

$25-29$

$30-34$

$35-39$

$40-44$

$45-49$

\section{Education}

No education

$0.40(0.38-0.44)^{\star \star}$

Primary

Secondary

Higher

Highest Educational level of husband/partner

No Education

Primary

Secondary

Higher

Don't know

\section{Marital Status}

Never in union

Married

Living with partner

Other (widowed/divorced)
aOR $(95 \% \mathrm{Cl})$

$1.24(1.13-1.35)^{\star *}$

$1.66(1.55-1.79)^{* *}$

$1.68(1.56-1.79)^{\star \star}$

$1.69(1.58-1.80)^{\star \star}$

$1.58(1.48-1.70)^{\star \star}$

1 $1.67(1.56-1.78)^{\star \star}$ $0.82(0.77-0.88)^{\star *}$

$0.89(0.84-0.95)^{*}$
1

$1.33(1.17-1.50)^{\star \star}$

$1.26(1.10-1.43)^{*}$

$1.30(1.10-1.54)^{*}$

$1.24(0.93-1.68)$

Multiple logistic regression: Dependent variable - Use of Modern Contraceptive (use/non-use) ${ }^{* *} p<$ 0.001; ${ }^{*} p<0.01$. aOR-Adjusted Odds Ratio: 95\% Cl: 95\% Confidence Interval. 1-Reference category. 
Age group (years)

\section{Place of Residence}

Urban

Rural

Employment

No

Yes

Religion

Christian

Islamic

Traditional

Other

Wealth Index

Poorer/poorest

Middle

Richer/Richest

\section{Age at first birth}

no birth

$<20$

$20-29$

$29+$

\section{Number of living Children}

None

$1-2$

$3-4$

5-7
aOR $(95 \% \mathrm{Cl})$

1

$0.76(0.72-0.89)^{\star \star}$

1

$1.03(0.99-1.06)$

$0.66(0.60-0.72)^{\star \star}$

$0.46(0.39-0.55)^{*}$

1

$0.76(0.73-0.79)^{\star \star}$

$0.89(0.85-0.93)^{\star \star}$

1

1

$0.98(0.80-1.20)$

$0.88(0.72-1.08)$

$0.56(0.45-0.71)^{\star \star}$

Multiple logistic regression: Dependent variable - Use of Modern Contraceptive (use/non-use) ${ }^{\star \star} p<$ 0.001; ${ }^{*} p<0.01$. aOR-Adjusted Odds Ratio: 95\% Cl: 95\% Confidence Interval. 1-Reference category. 


\begin{tabular}{|c|c|}
\hline Age group (years) & aOR $(95 \% \mathrm{Cl})$ \\
\hline $7+$ & 1 \\
\hline \multicolumn{2}{|c|}{ Number of sex partner (s) excluding spouse } \\
\hline None & 1 \\
\hline 1 & $4.22(4.00-4.45)^{\star \star}$ \\
\hline 2 & $7.31(6.34-8.43)^{\star *}$ \\
\hline $3+$ & $9.57(6.62-13.84)^{\star \star}$ \\
\hline \multicolumn{2}{|c|}{ Told of family planning at a health facility } \\
\hline No & $0.69(0.67-0.71)^{\star \star}$ \\
\hline Yes & 1.00 \\
\hline \multicolumn{2}{|c|}{ Heard of family planning on Media } \\
\hline No & $0.77(0.74-0.79)^{\star \star}$ \\
\hline Yes & 1.00 \\
\hline \multicolumn{2}{|c|}{ Knowledge of modern method } \\
\hline No & 1 \\
\hline Yes & $303.8(89.9-1027.5)^{\star \star}$ \\
\hline \multicolumn{2}{|c|}{ Fieldworker visited and talked about family planning } \\
\hline No & 1 \\
\hline Yes & $1.53(1.39-1.68)^{\star \star}$ \\
\hline \multicolumn{2}{|c|}{ Visited Health Facility last 12 months } \\
\hline No & 1 \\
\hline Yes & $1.26(1.16-1.36)^{\star \star}$ \\
\hline
\end{tabular}

\section{Figures}




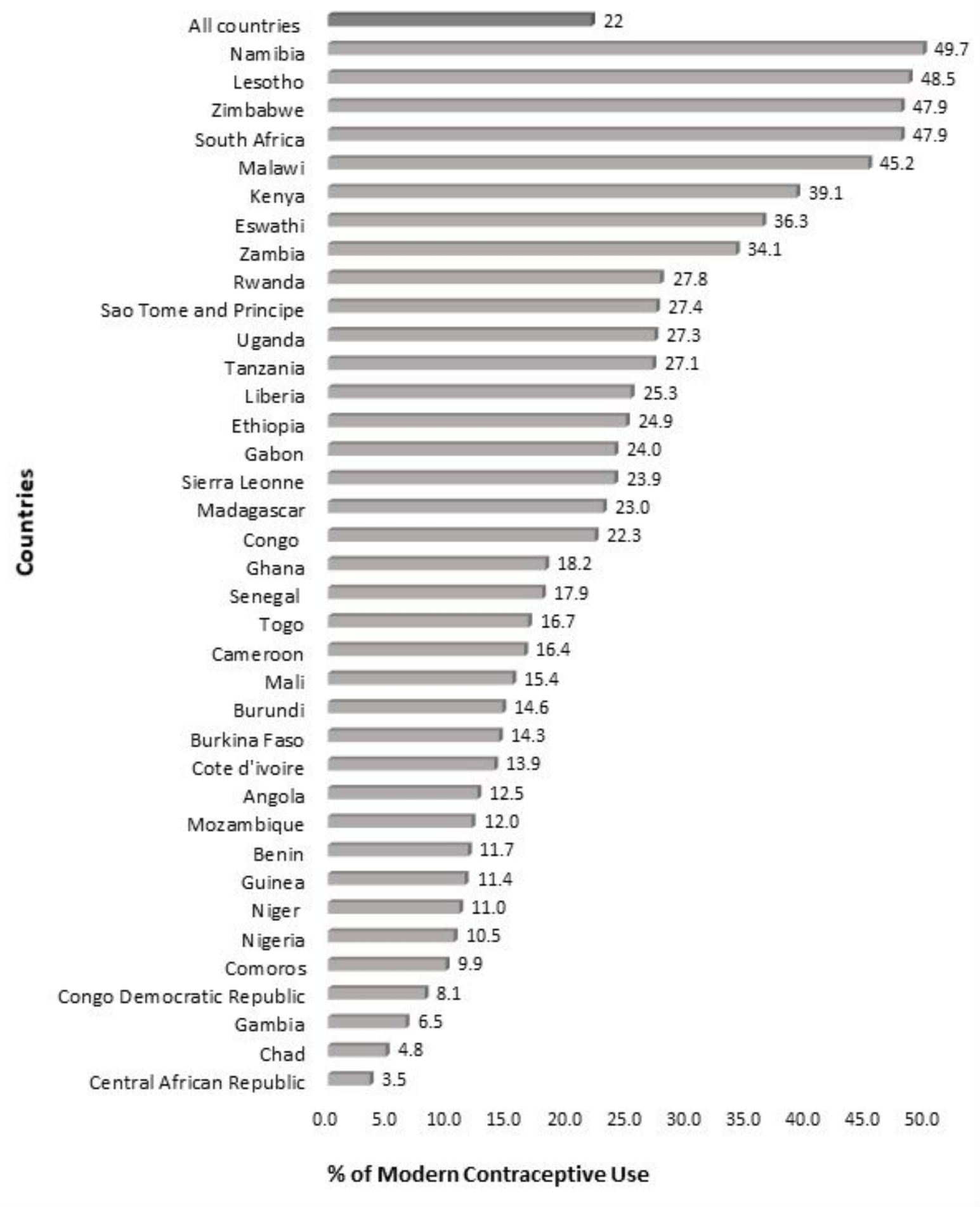

\section{Figure 1}

Prevalence of MC use among Women (14-59) years in Sub-Sahara Africa The pooled prevalence of modern contraceptive use was $22.0 \%$ (95\% Cl: 21.8 - 22.2\%). Coverage varied considerably across countries, ranging from the highest, $49.7 \%$ (95\% Cl: $48.4-51.1 \%)$ in Namibia to lowest, $3.5 \%$ (95\% Cl: 3.0 - 4.1\%) in Central Africa Republic 


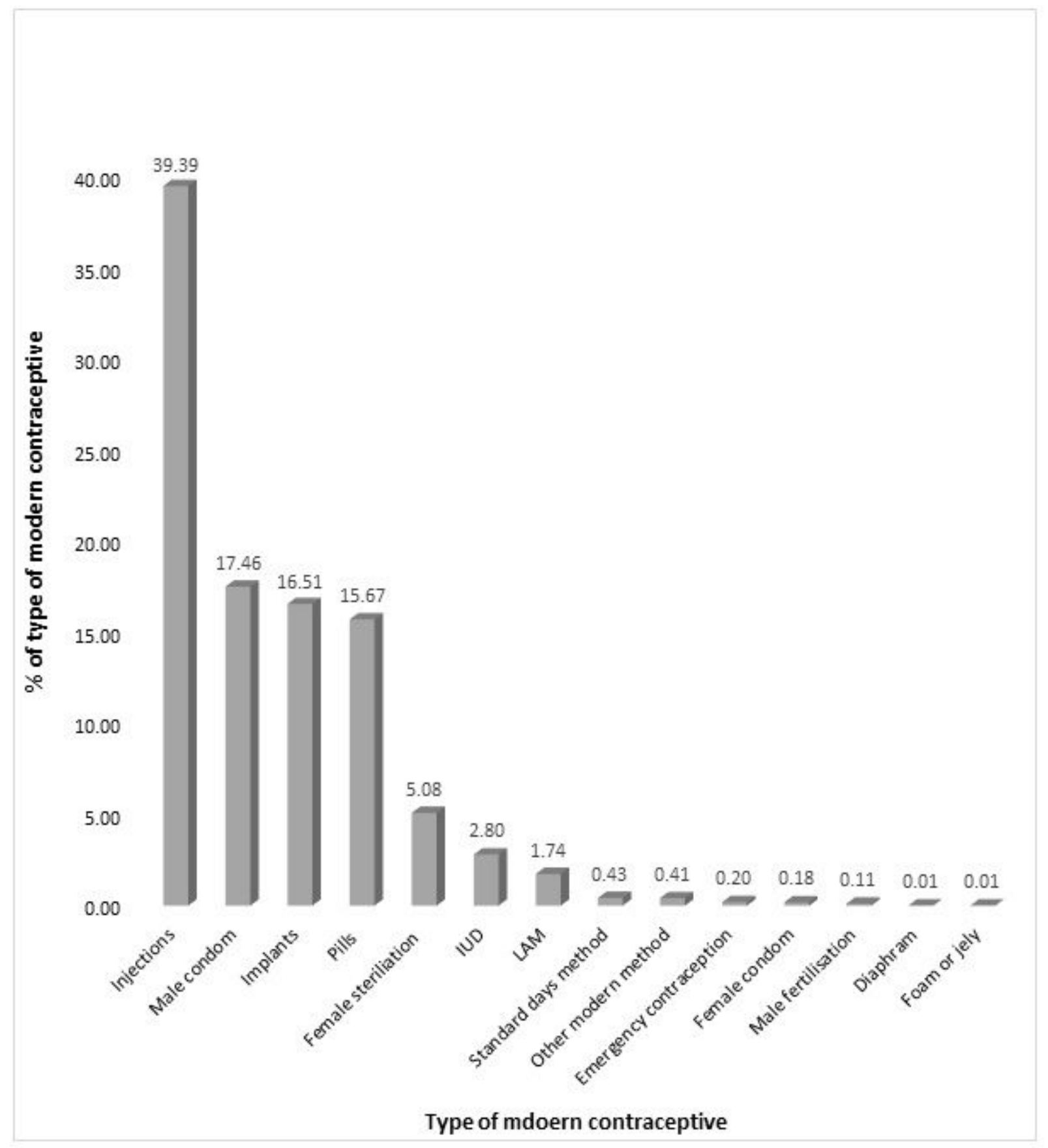

Figure 2

Type of modern contraceptive used The most commonly used family planning method (modern contraceptives) were injections (39.4\%), male condoms (17.5\%), implants (16.5\%), and pills (15.7\%). 